Article

\title{
Farmers' Willingness to Pay for New Storage Technologies for Maize in Northern and Central Benin
}

\author{
Evelyne Gbénou-Sissinto $^{1, *}$, Ygué P. Adegbola ${ }^{2}$, Gauthier Biaou ${ }^{1}$ and Roch C. Zossou ${ }^{2}$ (D) \\ 1 Department of Economy and Sociology of Rural Development, Agricultural Sciences Faculty (FSA), \\ University of Abomey-Calavi (UAC), Cotonou 01BP526, Benin; gauthier.biaou@una.bj or gbiaou@yahoo.fr \\ 2 National Agricultural Research Institute (INRAB), Cotonou 01BP884, Benin; \\ patrice.adegbola@yahoo.fr (Y.P.A.); rochybuggs@yahoo.fr (R.C.Z.) \\ * Correspondence: evesinto@yahoo.fr; Tel.: +229-97-052-774
}

Received: 11 June 2018; Accepted: 9 August 2018; Published: 17 August 2018

\begin{abstract}
The aim of this study is to identify the attributes of storage structures sought by maize producers based on a choice experiment. The experimental processes took place in the maize production areas of northern and central Benin. The sample consisted of 365 maize farmers (80.55\% male and $19.45 \%$ female) randomly selected from 40 villages. Data were collected and analyzed using a latent class logit model to study the heterogeneous preferences of the key attributes of storage structures. The results show that men and women are eager to change their current practices and to adopt new storage technologies. The study identifies four potential producer segments, including three large-farmer segments that have access to credit and are particularly attracted to structures related to metal silos. Of those three segments, two are also attracted to improved traditional silos. Another segment of poor farmers, who do not have access to credit, prefer to have a very efficient structure (loss rate of less than 5\%) that is designed with local materials. This study suggests that knowledge of the heterogeneity of preferences, as well as the preferred attributes, is important for the development and dissemination of better technologies by agribusiness firms, institutions and policymakers.
\end{abstract}

Keywords: maize; storage structures; choice experiment; latent class logit model; willingness to pay; Benin

\section{Introduction}

Food losses in West Africa and Southeast Africa are estimated at 120-170 kg/year, with $40 \%$ of losses occurring in the post-harvest and processing stage [1]. Losses are estimated at approximately 15-20 million tons of cereals [2]. Post-harvest losses for cereals alone account for more than US \$4 billion, i.e., $15 \%$ of the total production value [3]. Food security is a major challenge in Sub-Saharan Africa mainly for food-deficit countries. The 2008 food and financial crises have heightened the focus on post-harvest losses. Indeed, an important part of the production is lost or wasted throughout the crop value chain from the initial agricultural production down to final household consumption. Pest damage during storage is a serious constraint to both food security and households' income in sub Saharan Africa. Insects cause both grain weight and quality losses [4]. Moreover, the stored maize may also be contaminated by pathogenic agents due to rodents that feed on maize. This can have a severe impact on public health. Tefera [5] argued that traditional storage practices in developing countries do not offer safe protection against major pests attacking food products such as maize, leading to $20-30 \%$ losses. Farmers in developing countries have highly variable post-harvest losses (5 to 30\%) depending on weather conditions, harvest, shelf life and the presence of parasites [6]. Thus, small farmers are 
frequently forced to sell their grain earlier than they would like and buy it back as maize at a higher price a few months after harvest.

Maize is the major cereal and staple food that is an important source of income and employment for many farmers in Benin. The estimated per capita annual consumption was $136 \mathrm{~kg}$ in 2002 [7]. The average annual maize production and areas over the five-year period (2009-2014) accounted for $78 \%$ of annual total cereal production and for $82 \%$ of the total cereal area. Maize is stored in traditional storage structures at village level and treated with protectant products. Although these structures and conservation products in some cases seem to be adapted to the prevailing environmental conditions, they are not always effective in protecting maize against pest infestation, leading to storage losses. In Benin, estimates of losses after six months of storage range from $17 \%$ to $40 \%$ of the total maize production $[8,9]$. In response to high rates of maize storage losses, granaries and insecticides to protect grain in storage are being developed or adapted and diffused for use by producers in Benin since 1960 . Except the improved wooden and earthen made granaries and Sofagrain ${ }^{\circledR}$, a commercial insecticide for use in stored grain, none of the storage innovations was adopted [10]. Adégbola et al. [11] studied the factors leading to the adoption of plant material-based improved granaries for storing maize in southern Benin and concluded that dissemination remains one important element of adoption. While studying the financial profitability of storage structures, Arouna et al. [12] concluded that "building improved clay granaries requires that the farmer invests nearly twice the cost of traditional granaries". Adebayo et al. [13] evaluated the improved traditional storage structures of wood granaries and improved mud granaries in two (02) regions of Nigeria and came to the conclusion that losses are mostly due to pests, as these granaries do not maintain the required anaerobic environment that is harmful to pests. The World Bank [3] observed that even improved traditional granaries have been abandoned due to a lack of construction knowledge, a lack of space at homes and difficulties in moving traditional granaries during fires. These popular technologies did not correspond to producer expectations. Studies indicate that farmers' perceptions of the main characteristics of an innovation influence its expected relative value and subsequent adoption decisions [14-16]. Therefore, in addition to the technical characteristics, farmers' preferences for the characteristics of new storage technologies should be taken into account during its development process, if widespread adoption is to be achieved [17].

Few studies assess the characteristics perceived by farmers as important to the wide adoption of a new agricultural technology. Exceptions are the works of $[10,18]$. These studies, using an index approach developed by [19], assessed the desired characteristics of improved rice varieties and maize storage structures, respectively and how they match with rice and maize producers' needs. Other exceptions are the studies by [20-24]. These studies used a full profile approach, in which respondents' rate or rank preferences for a set of "total" hypothetical products or product profiles. The drawback of this approach is the possibility of information overload, particularly in developing countries such as Benin. Consequently, the respondents ignore the variations in the less important product's characteristics or simplify their levels. This leads to unrealistic results, not representative of the real-life behavior of the farmers. In addition, the segmentation of respondents is not straightforward. Cluster analysis is used to group the respondents based on the similarity of their estimated preferences and on their socio-demographic characteristics. Alternatively, heterogeneity is investigated by interacting respondent-specific characteristics with product characteristics or alternative product profiles. Very few articles available in the literature address farmers' preferences for key characteristics of agricultural technologies using a choice experiment (CE) approach and investigate preference heterogeneity as well as the willingness to pay (WTP) [25-29]. In addition, none of these referred to cereal or maize storage technologies. This is, therefore, the contribution of our study.

This study focuses on producer preferences for storage structures' attributes using a stated preference approach. There are other methods to address the preference such as the revealed preference method. The revealed preference data are obtained by observing individual behavior in a real situation. This is not used because the storage structures' profiles that may be wanted by respondents do not yet 
exist and are hypothetical. Stated preference is a research methodology that clarifies information about the preferences of decision-makers by confronting them with different hypothetical alternative choices previously devised by the analyst [30-32]. The stated preference methodology offers the opportunity to estimate the demand for non-existent technology attributes.

The objective of this study is three-fold. First, we assess farmers' preferences for storage structures by investigating the importance of storage structures' characteristics on farmers' choice of storage structures in northern and central Benin. Second, through the results of the first step, we estimate farmers' willingness to pay (WTP) for the hypothetical storage structures or attributes. Third we investigate heterogeneity among maize producers based on their preferences for individual or groups of characteristics embodied in indigenous and/or new storage structures. Insight into the technological characteristics demanded by farmers and understanding the differences across their segments may guide the generation of appropriate storage structures. In addition, promotion and advertising programs may be designed to target maize growers in the segment for the wide adoption and diffusion of storage structures.

The choice experiment (CE) approach is used to achieve the objectives of this study. The latent class logit model (LCL) is applied in the empirical model to estimate the probability that a maize producer simultaneously chooses a given storage structure from a set of choices, based on his preferences for the key storage structure attributes and belonging to a specific segment. Apart from the CE, basic information about the socio-economic characteristics of maize producers was also collected. Results show that farmers are likely to adopt new storage structures. This study identifies four potential producer segments, including three large-farmer segments that have access to credit and show a strong preference for the metal silos.

The remainder of this article is as follows: The next section describes the materials and the discrete choice experiment method as well as the empirical model used. Section three presents the estimation results. The findings of this study are discussed in Section 4 . The final section provides conclusions and implications for the generation and dissemination of appropriate storage structures for each farmer's segment.

\section{Materials and Methods}

\subsection{Study Area}

This study was conducted in northern and central regions of Benin in West Africa. The country covers an area of $114.763 \mathrm{~km}^{2}$ and is located in the tropical zone between the equator and the Tropic of Cancer between parallels $6^{\circ} 30^{\prime}$ and $12^{\circ} 30^{\prime}$ north latitude and meridians $1^{\circ}$ and $30^{\circ} 40^{\prime}$ east longitude. It is bordered to the south by the Gulf of Benin, to the East by the Federal Republic of Nigeria, to the west by the Republic of Togo and to the north by the Republics of Burkina-Faso and Niger. Since 2016, it is divided into seven poles of agricultural development. This zone is characterized by the Sudano-Sahelian and Sudano-Guinean weather zones, and crop production is dominated by cereals. Cereal production is growing at an annual average rate of $6.5 \%$; this value is higher than the growth rate of the population, which is estimated at 3.5\% annual growth [33]. This growth is mainly driven by the cultivation of maize, the main staple food of the Benin population.

\subsection{Sampling}

The sampling approach used for the study was a 2-stage stratified simple random technique. To take into account the weather conditions as well as the factors that influence the use of the maize storage structures and the results of the producers, a stratification was done according to department at the level of agricultural development poles (PDA). Benin has been divided into seven agricultural development poles (Figure 1), which are areas with the same agro-climatic conditions and which include several departments. 


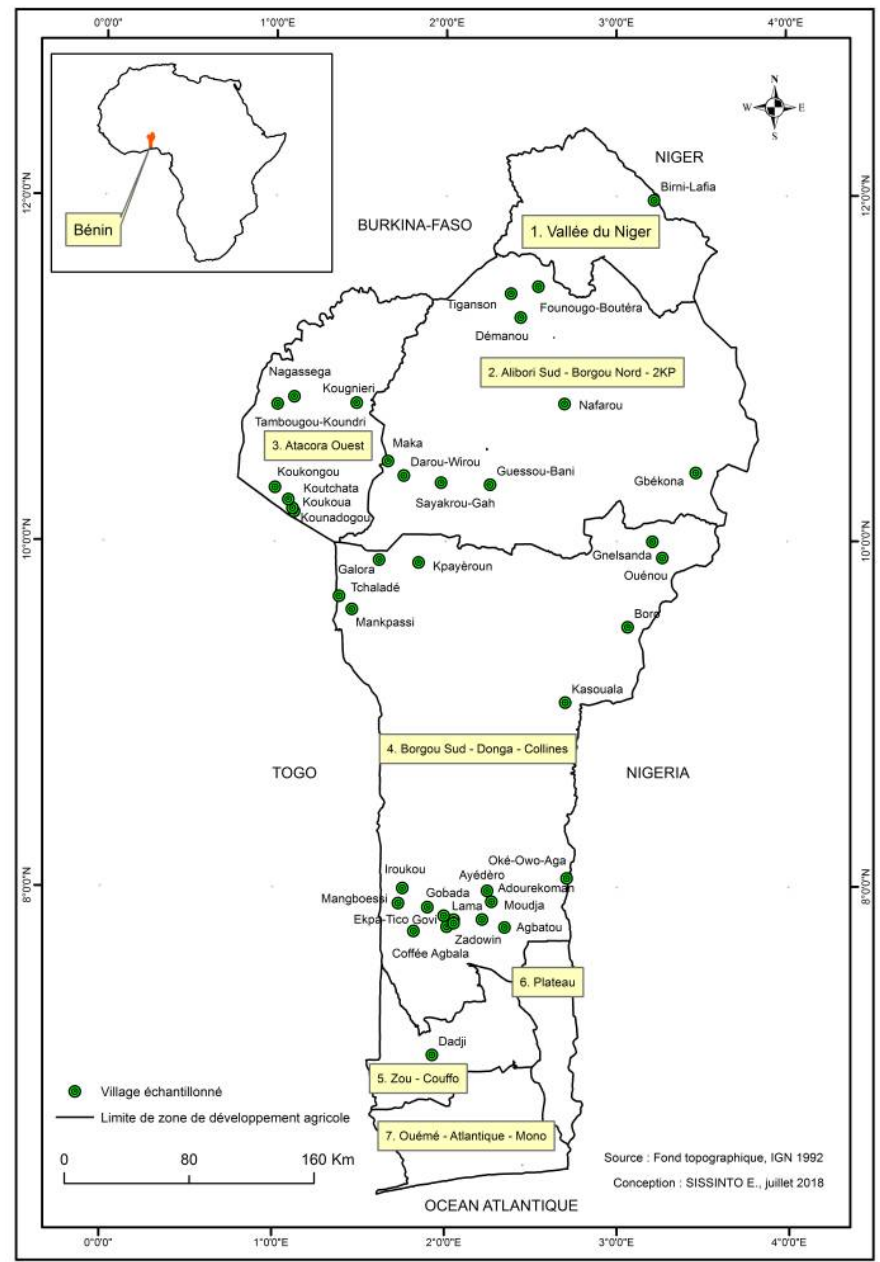

Figure 1. Study area in Benin.

Based of maize production statistics for the last ten (10) years by department and by municipality, and the results of a farm characterization study (village level) conducted by the National Program for the Analysis of Agricultural Policies [34], providing the basic statistics of maize production by village, the number of villages producing maize in each department in each PDA was assessed. Using the Dillman [35] formula, the number of villages to be surveyed in each department was determined. In each department, the villages were randomly selected using the Excel "Random" from the list of maize producing villages. Thirty-nine (39) villages in twenty-one (21) municipalities in five (5) departments were selected based on the volume of maize production.

At the level of the selected villages, the number of maize farmers to be surveyed was set at 10 farmers per village. These farmers (390) were randomly selected from the 39 maize producing villages in northern and central Benin. In total, 365 farmers were interviewed out of 390 planned. The survey unit was composed of 365 farmers and maize stockers ( $80.55 \%$ male and $19.45 \%$ female) randomly selected from thirty-nine (39) maize production-area villages in northern and central Benin.

The exploratory survey took place in June 2017 and the questionnaire was developed in July 2017. The pre-test was done in three rounds of interviews in July 2017 and minor corrections and modifications were added to the questionnaire. The questionnaire was divided into five parts: the general characteristics of the area; the respondents' characteristics; the storage practices; the importance of the choice attributes, and the choice of storage structures. The survey was conducted in August 2017, using face-to-face interviews in local languages of the respondents and data were registered on tablets. 
To minimize the biases that may affect the quality of collected information, the entire team (authors, supervisors and enumerators) clearly explained, and agreed on, the objectives, concepts, and pictorial descriptions of the profiles. In the field, the enumerators explained the concepts and objectives of the survey and presented pictorial descriptions (attributes and levels) of the profiles to the respondents.

Each respondent was not to choose the q0 status more than twice in all of the choices if they had to opt for his current practice $[28,36]$. He was, therefore, forced to give importance to the different profiles in play.

\subsection{Conceptual Framework}

\subsubsection{Choice Experiment (CE) Approach}

Lancaster's theory of economic agent behavior [37] identifies choice experiences or preferences. Preference of study methods (conjoint analysis, contingent valuation, choice experiment etc.) usually focus on the theory of random utility and rely on assumptions of economic rationality and utility maximization $[38,39]$. The choice experiment method is very popular and provides a solid base for stated preference studies by providing the benefits sought by different individual categories [40-42]. Several choice experiment data collection approaches have emerged, and the one related to the discrete approach is much easier than the other approaches [42-44]. To analyze discrete choice data, most models use the random utility theory $[45,46]$. In random utility models, the probability of observing a specific fulfillment of the choice being modeled is determined by a decision rule formulated as latent or unobservable variables associated with choice [47]. Thus, the indirect utility $(U)$ that a producer $(i)$ receives from a structure's attributes for an alternative $(j)$ takes the following linear form:

$$
U_{i j}=V_{i j}+j \varepsilon_{i j} j=1, \ldots, \mathrm{K} \text { and } i=1, \ldots, n
$$

where $V_{i j}$ is the deterministic (non-stochastic) part of the utility and $\varepsilon_{i j}$ is the random part (or stochastic part consisting of the model error terms), which takes into account uncertainty. Depending on the hypotheses adopted to represent the distribution of the random part, different models of discrete choice can be distinguished. Mathematically, discrete choice models are generally based on the hypothesis that utility function choice probabilities can be estimated by using the multinomial logit model (MNL) [48]. However, this model has limitations related to Gumbel's hypothesis of identically distributed independence (IDI) of error terms between alternatives and observations and thus presumes a homogeneity of preferences $[49,50]$. Another major deficiency of the MNL is related to the independence of irrelevant alternatives (IIA) hypothesis [46]. To overcome these limitations, the alternative flexible models that are used the most are mixed logit, (MXL), random parameters logit (RPL), error component logit, (ECL), generalized multinomial logit, latent class (LCL) model, etc. [38,46,49]. The MXL makes it possible to detect any unobserved heterogeneity in preferences [26]. The LCL model does not violate the IIA hypothesis and differs from the MXL model, as it admits that coefficient distribution can be discrete rather than continuous. It uses a statistical methodology based on the concept of likelihood to identify the sources of heterogeneity at the segment level rather than the individual level, similar to the MXL model [27]. This model is increasingly applied in recent segmentation studies and generates good results $[25,27,28]$.

\subsubsection{Latent Class Logit Model}

The latent class logit model estimates the probability that a producer simultaneously chooses a given technology from a set of choices and belongs to a specific segment [25]. Considering a producer, $i$, who chooses an alternative, $j$, from among $K$ alternative technologies in a set of choices; assuming 
that the producer belongs to a customer segment $s$ with $s \in S$, the indirect utility function for the producer's preferred technology profile, $j$, is written as follows:

$$
U_{i j / s}=X_{i j} \beta_{s}+\varepsilon_{i j / s}
$$

where $X_{i j}$ is a vector representing the attributes related to $K$ alternatives, $\beta_{s}$ is the s segment and the parameter vector associated with the vector $X_{i j}$ and $\varepsilon_{i j / s}$ is an error term. Assuming that error terms are independently and identically distributed (IID) and comply with the Gumbel distribution, the probability that producer $i$ chooses an alternative from among the $K$ alternatives while belonging to a given segment is:

$$
P_{K / s}=\prod_{1}^{k} \frac{\exp (X i j \beta s)}{\sum_{1}^{k} \exp (X i k \beta s)}
$$

Now, let us consider $M_{n s}^{*}=\lambda_{s} Z_{n}+\xi_{n s}$ to be a function of the probability $\left(P_{s}\right)$ of belonging to a segment (s) among the $S$ unobservable segments, where $Z$ represents the socio-demographic characteristics of the producer and $\lambda_{s}\left(s=" 1.2,3, \ldots S^{\prime \prime}\right)$ represents the specific parameters used to estimate each segment. We assume that the error terms, $\xi_{n s}$ are independently and identically distributed among farmers and segments and align with a Gumbel model. The probability that a producer belongs to a segment, $s$, can be expressed as follows:

$$
P_{s}=\frac{\exp \left(\lambda_{s} Z_{n}\right)}{\sum_{1}^{S} \exp \left(\lambda_{S} Z_{n}\right)}
$$

By combining Equations (3) and (4), we obtain the following expression representing the probability that a producer $i$ belongs to a segment $\mathrm{s}$ and chooses the technology profile $j$ :

$$
P_{j n / s}=\sum_{1}^{S} P_{s} P_{K / s}=\sum_{1}^{S}\left(\frac{\exp \left(\lambda_{s} Z_{n}\right)}{\sum_{1}^{S} \exp \left(\lambda_{S} Z_{n}\right)} \prod_{1}^{k} \frac{\exp (X i j \beta s)}{\sum_{1}^{k} \exp (X i k \beta s)}\right)
$$

The log function of likelihood to be maximized to obtain parameters $\lambda_{s}$ and $\beta s$ is expressed as follows:

$$
L=\sum_{k} \sum_{n} I_{i} \ln P_{j n / s}
$$

where $I_{i}$ is an indicator variable of the choice observed.

The parameters estimated from latent class logit models can also be used to calculate WTP for each attribute, which helps in understanding the respondents' motivations and quantifying their preference levels for the attributes. Supposing there is an attribute $X_{1}$ for which we want to estimate WTP1. The estimated parameter $\beta_{1}$ of the attribute $X_{1}$ can be interpreted as the marginal utility of this attribute. In addition, let us call $\delta$ the parameter estimated for the cost attribute, i.e., "the structure or product cost", which represents the marginal utility of money [51]. The marginal consent to pay associated with the attribute $X_{1}$ is expressed by the following formula:

$$
C A P 1=-\frac{\beta_{1}}{\delta}
$$

According to the authors of $[28,29,52]$, implementing a choice experiment involves the following steps: identification of relevant attributes and definition of terms, development and presentation of profiles for the collection of preferences, data collection and data analysis.

\subsubsection{Identification of Relevant Attributes and Attribute Levels}

Since the choice experiment survey technique is characterized by a statistical design of hypothetical profiles [52], theoretical profiles of storage structures were designed from the main attributes and levels of the declared choice attributes. The analysis of the exploratory phase data with 
a focus group was conducted using an interview guide developed on the basis of previous studies, which helped to identify an exhaustive list of the main attributes (Table A1 in Appendix A). As a result, six (06) main attributes were selected using the Kendall ranking method. The following attributes and their associated definitions and attribute levels were used during the experiment of choice (Table 1).

Table 1. Storage Structure Attributes and Attribute Levels.

\begin{tabular}{|c|c|c|c|}
\hline & Attributes & Description & Attribute Levels \\
\hline 1 & Capacity & $\begin{array}{l}\text { Contain of storage structure is determined by the } \\
\text { volume of maize production. }\end{array}$ & $\begin{array}{l}1=\text { Large }(>500 \mathrm{~kg}) \\
2=\text { Medium }(250-500 \mathrm{~kg}) \\
3=\text { Small }(25-250 \mathrm{~kg})\end{array}$ \\
\hline 2 & Storage shape & Storage form & $\begin{array}{l}1=\text { Grain } \\
2=\text { Cobs } \\
3=\text { Stalk }\end{array}$ \\
\hline 3 & Efficiency & $\begin{array}{l}\text { Effectiveness against pest attacks based on the } \\
\text { rates of losses }\end{array}$ & $\begin{array}{l}1=\text { Very effective }(<5 \% \text { loss }) \\
2=\text { Less effective }(5-30 \% \text { loss }) \\
3=\text { Not effective }(>30 \% \text { loss })\end{array}$ \\
\hline 4 & $\begin{array}{l}\text { Type of building } \\
\text { material }\end{array}$ & $\begin{array}{l}\text { Local (traditional or improved) and imported } \\
\text { materials }\end{array}$ & $\begin{array}{l}1=\text { Imported } \\
2=\text { Improved } \\
3=\text { Traditional }\end{array}$ \\
\hline 5 & Life span (years) & Length of life of storage structure & $\begin{array}{l}0=\operatorname{long}(>4 \text { years }) \\
1=\text { short }(<4 \text { years })\end{array}$ \\
\hline 6 & Cost (FCFA) & Price of building or of purchase (FCFA) & $\begin{array}{l}600 ; 15,000 ; 25,000 ; 40,000 \\
50,000 ; 110,000\end{array}$ \\
\hline
\end{tabular}

The volume of maize production naturally specifies the structure capacity $[10,53]$. One can assume heterogeneity in preferences, as some farmers will prefer large-capacity structures, and others will prefer small-capacity structures. The storage shape (grain, cobs or stalks) guides their choice of structure [53,54]. The introduction of plastic cans, bags and improved silos equipped with a drainage valve by research agencies and NGOs has led farmers to first shell the maize to store it in the form of grain $[53,55]$. This form of preservation facilitates destocking and pest control operations. We therefore state the hypothesis that grain maize storage will be more preferred. The shape and materials of storage used vary from one area to another depending on agro-climatic requirements, ethnological factors and some socio-economic conditions [56,57] and the financial means, the non-availability of building materials and the lack of building skills $[10,54,58]$. The efficiency of storage structure trial results showed that losses ranged between $5 \%$ and $30 \%$. Other categories of structures, such as metal silos and bags, have been developed recently, reducing losses to a rate of less than 5\% [55,59]. We assume that storage structures that are more effective against pest attacks will be more preferred. For life span, we assume that farmers will particularly prefer structures that have a long life span, which will allow them to save money over many years. Earlier research on technology adoption has shown that the cost of acquiring new technologies is still high and often hinders their adoption [11,60]. We then state the hypothesis that low-investment cost will be more attractive than storage structures requiring a high-initial investment cost.

\subsubsection{Creation of Choice Sets}

Given the number and level of attributes, $3^{4} \times 2^{1} \times 6^{1}=3 \times 3 \times 3 \times 3 \times 2 \times 6=972$ possible alternatives or theoretical profiles could be constructed. It would have been very difficult for the respondents to objectively consider 972 profiles before making a specific choice. To facilitate their choice, the discrete choice sets were restricted to twenty (20) realistic profiles divided into five (05) groups of four $(04)$ profiles each $(5 \times 4)$ using the D-efficiency criterion, Dz, estimated at $97.81 \%$ [52]. This result was obtained through the SAS package using the experimental design proposed by 
Street and Burgess (2007), which is based on the optimality criteria method for effective design. Among the theoretical profiles thus created, nine (9) existing storage structures (profiles 3, 4, 5, $10,12,13,14,17,19)$ (Table A2 in Appendix A) were identified through their characteristics and considered in the choice sets along with the hypothetical structures. A reference case condition (status q0) was added to each choice set. This status q0 referred to the actual storage practice used by each respondent. These characteristics were functions of the principal attribute levels and were inherent to each respondent. Different standard storage structure profiles were presented to each producer as a game. For each set of choices, the producer had to declare a preference for a profile or to choose the reference case that corresponded to his/her current practice. Each respondent selected the fictitious alternative that gave him/her the greatest benefit. To facilitate the understanding of the respondents, the various scenarios were provided as illustrated pictures together with a brief description. The various participants were assured that their virtual choice in the experiment would not affect their activities. It was clarified that the results would be used to determine an appropriate model for maize storage structures.

\subsubsection{Empirical Model}

In the experiment process, the men and women interviewed were asked to choose a technology profile or to choose their current practice (q0 status) from the choice set. The dependent variable $Y$ corresponds to the choice of a preferred profile of the producer in each set of choices. It has the value $Y=1$ for the profile that the respondent chose and the value $Y=0$ for the options that were not chosen. In the model specification, the degree to which an individual benefits from a profile model depends on the main attributes of the technology and the producer's characteristics [37,38].

Note that attributes with more than three levels have been disaggregated $\left(n^{-1}\right)$ by considering an attribute level as a reference. In the model, the cost coefficient is fixed, and the other attributes have random parameters for which we assume a normal distribution in the sample. The reference case or current practice (status q0) was used in the model. A negative sign for the variable coefficient would generally imply that farmers are motivated to adopt new storage technologies.

In addition to the storage structure's attributes, a producer's individual characteristics and the characteristics of his/her farm and residence area, which can be used to identify the producer's segment, can affect the producer's acceptance or rejection of storage structures $[25,28,61]$. According to studies, these characteristics may include gender, years of experience in the maize storage sector, production capacity, stored capacity for sale, maize revenue, participation in experiments [62,63], access to credit, household size, membership in a cooperative/producer group, and distance from the producer's village to the periodic market [12,53,56,64-67].

Not all of these explanatory variables were included in the latent class logit model estimate. A correlation matrix eliminated the highly correlated variables and those that did not demonstrate some alternative variability. Variables such as the number of bags produced and the area sown were not included in the model because the correlation threshold between these variables and income was very high. As a result, farmers with higher incomes were those growing large farms and producing large amounts of maize. The characteristics included in this model were gender, years of experience in the maize storage sector, stored quantity for sale, participation in tests and access to credit. Table 2 presents the explanatory variables included in the storage structure model. 
Table 2. Description of Model Variables.

\begin{tabular}{ccc}
\hline Variable & Modality & Expected Sign \\
\hline Cost a & Continuous variable & - \\
Status q0 & 1 $=$ YES, $0=$ if applicable & - \\
Medium Capacity $\left(1^{*}\right)$ & $1=$ YES, $0=$ if applicable & $+/-$ \\
Large Capacity $\left(1^{*}\right)$ & $1=$ YES, $0=$ if applicable & $+/-$ \\
Stored as cobs $\left(2^{*}\right)$ & $1=$ YES, $0=$ if applicable & - \\
Stored as stalk $\left(2^{*}\right)$ & $1=$ YES, $0=$ if applicable & - \\
Less effective storage structure $\left(3^{*}\right)$ & $1=$ YES, $0=$ if applicable & $+/-$ \\
Highly effective storage structure $\left(3^{*}\right)$ & $1=$ YES, $0=$ if applicable & + \\
Type of materials: Improved $\left(4^{*}\right)$ & $1=$ YES, $0=$ if applicable & $+/-$ \\
Type of materials: Imported $\left(4^{*}\right)$ & $1=$ YES, $0=$ if applicable & + \\
Life span & $1=$ YES, $0=$ if applicable & + \\
Gender & $1=$ Man, $0=$ Woman & \\
Years of experience in storage & Continuous variable & \\
Stored quantity for sale & Continuous variable & \\
Participation in on-farm trials & $1=$ YES, $0=$ if applicable \\
Access to credit & $1=$ YES, $0=$ if applicable & \\
\hline
\end{tabular}

$\left(1^{*}\right)$ Reference: low capacity; $\left(2^{*}\right)$ Reference: storage in the form of grain; $\left(3^{*}\right)$ Reference: Less effective; $\left(4^{*}\right)$ Reference: Type of materials for building traditional storage structures.

\section{Results}

\subsection{Socio Demographic Characteristics of the Respondents}

The respondents' socio-economic and demographic characteristics and the quantity of maize produced and stored according to gender are presented in Table 3. The results show that the proportion of male respondents $(80.55 \%)$ was significantly higher than the proportion of female respondents $(19.45 \%)$. Thus, the maize farmers were mostly males.

Table 3. Socio-demographic Characteristics of the Respondents.

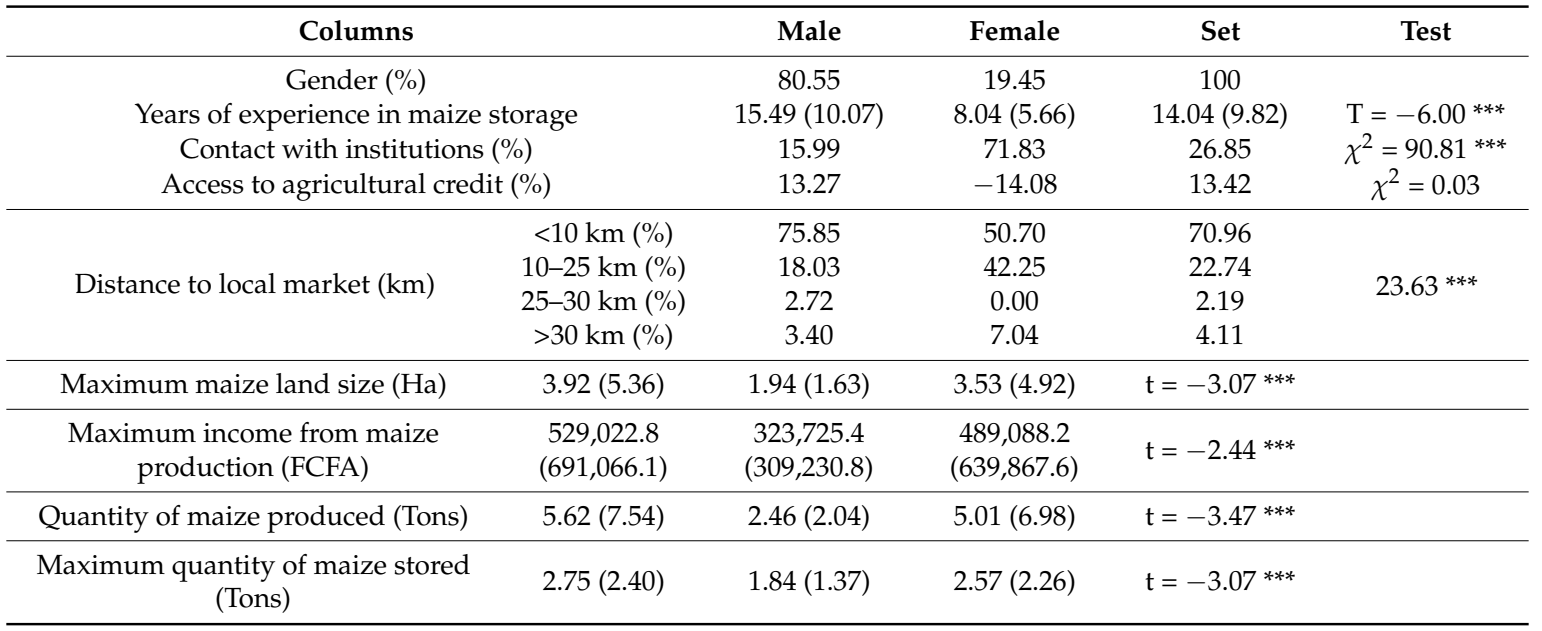

Note: ${ }^{* * *}$ indicates that the coefficients are significant at a $1 \%, 5 \%$ and $10 \%$ threshold, respectively; ( ... ): standard deviation.

The male participants were statistically more experienced in maize storage and conservation (15 years) than the female participants (8 years) $(p<0.01)$. The average number of years of experience in maize storage for all the respondents (14 years) emphasizes not only the maize farmers' level of maturity but also their experience in the storage and conservation of maize.

Less than $27 \%$ of the respondents had contact with institutions that work on improving technologies for storage and conservation. However, statistically, the proportions varied according to gender. Indeed, more than $71 \%$ of the female sample had contact with these organizations, whereas 
only $15.99 \%$ of the male respondents had contact with such organizations. We therefore conclude that the women were more informed than the men.

From the respondents, only $13.42 \%$ had access to credit for the past five (05) years. There was no significant difference according to gender. However, $13.27 \%$ of the men had access to credit compared with $14.08 \%$ of the women.

With regard to the distance between their houses and their local markets, the majority of the respondents were very close to their local market (less than $10 \mathrm{~km}$ ). A very small proportion $(7.30 \%)$ lived far from their local market. The statistical test shows that distance from the local market varied by gender. Indeed, over $75 \%$ of the men were located at a distance of less than $10 \mathrm{~km}$ from their local market, while only $51 \%$ of the women lived less than $10 \mathrm{~km}$ from their local market. Therefore, the men had more access to their local markets than the women. Nevertheless, $42.25 \%$ of the women were somewhat close to a market $(10-25 \mathrm{~km})$.

The maize fields of the respondents were no larger than $3.53 \mathrm{ha}$. The males had fields and incomes that were statistically nearly twice those of females $(p<0.01)$. The maize fields and the average income of the male respondents was estimated at 3.92 ha for 529,022.8 FCFA (807,67 euros). In contrast, the maize fields of the female respondents were only 1.94 ha and they earned an average income of 323,725.4 FCFA (494,24 euros). This shows how hard it is for women to have access to production assets (land, farm machinery, inputs, etc.) in Benin growing areas. A high proportion of the male respondents were considered to be big farmers.

Similar to growing fields, we also noted that the volume produced by the male respondents was statistically more than twice that produced by the female respondents with a $10 \%$ threshold. Indeed, the men produced an average of 5.62 tons compared with 2.46 tons for the women. In addition, the quantity of maize stored from production for all the respondents averaged 2.57 tons. However, the observed difference was not statistically significant by gender. Indeed, the male respondents had 2.75 tons stored, whereas the female respondents had 1.84 tons. The difference in terms of growing field and quantity of maize produced and stored by male and female respondents is explained by the fact that the majority of male respondents are often heads of household with more access to production factors than female respondents. Moreover, male respondents have the responsibility to meet both food security for the household and sales objectives to cover other demands.

\subsection{Latent Class Logit (LCL) Estimates (Segmentation)}

The first step in estimating the latent class logit model was the determination of the optimal number of classes. To accomplish this, the Bayes information criterion (BIC), the Akaike information criterion (AIC) and the consistent Akaike information criterion (CAIC) were calculated [51,61]. The results show that the AIC was minimized to six (06) segments, while the BIC and CAIC were minimized to four (04) segments (Table 4). Six (06) segments are far too many, therefore, four (04) segments were selected to better explain the heterogeneity of preferences.

Table 4. Latent Class Logit Model Information Criteria.

\begin{tabular}{cccc}
\hline Number of Segments & AIC & BIC & CAIC \\
\hline 2 & 4082.28 & 4164.18 & 4185.18 \\
3 & 4015.04 & 4139.84 & 4171.84 \\
4 & 3938.96 & $4106.65 *$ & 4149.65 \\
5 & 3912.64 & 4123.24 & 4177.24 \\
6 & $3859.16^{*}$ & 4112.65 & 4177.65 \\
\hline
\end{tabular}

Note: * indicates the lowest AIC and BIC.

The results of the latent class logit model with four (04) market segments are presented in Table 5. The first level shows the utility coefficients associated with the attributes of the storage structures, 
while the second level presents producer-specific characteristics. The coefficients associated with the individual characteristics of the fourth segment of farmers were reduced to zero, i.e., segment 4 was considered the reference. The $R^{2}$ for the model was 0.64 ; this suggests a very good adjustment. The predicted probability that a producer belonged to segments S1, S2, S3 and S4 was $28.5 \%, 20.70 \%$, $27.30 \%$ and $23.5 \%$, respectively.

Table 5. Estimation of the Latent Class Logit Model.

\begin{tabular}{|c|c|c|c|c|}
\hline Attributes & Segment 1 & Segment 2 & Segment 3 & Segment 4 \\
\hline Cost of the storage structure (FCFA) & $0.36(0.06) * * *$ & $0.34(0.08) * * *$ & $0.21(-0.06) * * *$ & $0.11(0.07)$ \\
\hline Medium capacity $(250-500 \mathrm{~kg})\left(1^{*}\right)$ & $-3.01(0.37) * * *$ & $-0.14(0.24)$ & $-1.42(0.26)^{* * *}$ & $2.04(0.37)^{* * *}$ \\
\hline Large capacity $(>500 \mathrm{~kg})\left(1^{*}\right)$ & $-1.48(0.27) * * *$ & $-0.52(0.27)^{* *}$ & $-0.50(0.20) * * *$ & $2.46(0.46) * * *$ \\
\hline Stored as cobs $\left(2^{*}\right)$ & $-0.84(0.35) * *$ & $-0.12(0.18)$ & $-2.55(0.36) * * *$ & $-4.05(0.51) * * *$ \\
\hline Stored as stalks $\left(2^{*}\right)$ & $-2.61(0.46) * * *$ & $-1.08(0.22) * * *$ & $-1.13(0.38) * * *$ & $-2.19(0.83) * * *$ \\
\hline Less efficient (5-30\% loss) $\left(3^{*}\right)$ & $3.96(1.05) * * *$ & $0.57(0.23)^{* * *}$ & $55.81(1399.01)$ & $4.31(0.69)^{* * *}$ \\
\hline Very efficient $(<5 \%$ loss $)\left(3^{*}\right)$ & $4.71(1.04) * * *$ & $1.21(0.26)^{* * *}$ & $56.19(1399.01) *$ & $5.05(0.69) * * *$ \\
\hline Type of materials: Improved $\left(4^{*}\right)$ & $1.79(0.52) * * *$ & $-1.76(0.34) * * *$ & $-0.04(1.44)$ & $1.88(0.69)^{* * *}$ \\
\hline Type of materials: Imported $\left(4^{*}\right)$ & $0.39(0.45) * *$ & $-0.33(0.25)$ & $4.66(0.79) * * *$ & $2.24(0.72) * * *$ \\
\hline Long life span ( $>4$ years) & $0.77(0.22)^{* * *}$ & $0.33(0.18)^{* *}$ & $0.14(0.23)$ & $2.56(0.44)^{* * *}$ \\
\hline \multicolumn{5}{|c|}{ Socio-demographic characteristics } \\
\hline Gender (1 = Man; 0 = Women) & $0.06(0.53)$ & $1.06(0.66) * *$ & $0.80(0.86) *$ & \\
\hline Years of experience in storage & $0.01(0.30)$ & $1.48(0.44)$ & $0.25(0.40)$ & \\
\hline Stored maize volume (Ton) & $0.50(0.29)^{* *}$ & $-0.03(0.18)$ & $-0.55(0.16)^{* * *}$ & \\
\hline Maize income (FCFA per year) & $0.05(0.26)$ & $-0.72(0.29) * *$ & $0.68(0.27)^{* * *}$ & \\
\hline Access to credit $(1=$ Yes, $0=\mathrm{No})$ & $0.34(0.51)^{* *}$ & $-1.96(1.25)$ & $0.12(0.66) * *$ & \\
\hline Participation in on-farms trials $(1=$ Yes, $0=\mathrm{No})$ & $-0.76^{* *}$ & $-0.63(0.60) *$ & $-2.94(0.98) * * *$ & \\
\hline Distance to the market $(\mathrm{km})$ & $-0.17(0.19)$ & $0.89(0.27)^{* * *}$ & $-0.60(0.24) * * *$ & \\
\hline Probability of belonging to each class & 28.5 & 20.7 & 27.3 & 23.5 \\
\hline Constant & $-2.76(2.67)$ & $3.21(2.98)$ & $-6.10(3.32) * * *$ & \\
\hline Number of observations & \multicolumn{4}{|c|}{9125} \\
\hline Number of respondents & \multicolumn{4}{|c|}{365} \\
\hline Log likelihood & \multicolumn{4}{|c|}{-1690.34} \\
\hline$R^{2}$ & \multicolumn{4}{|c|}{0.64} \\
\hline
\end{tabular}

$* * *, * * *$ indicate that the coefficients are significant at the threshold of $1 \%, 5 \%$ and $10 \%$, respectively; ( ... ): Error types; $\left(1^{*}\right)$ Reference: low capacity (25-250 kg); ( $\left.2^{*}\right)$ Reference: storage in the form of grains; $\left(3^{*}\right)$ Reference: inefficient (>30\% loss); $\left(4^{*}\right)$ Reference: Type of materials for building traditional storage structures.

The results show that the coefficient of the variable related to years of experience in maize storage is not significant regardless of class. This indicates that farmers with the same number of years of experience in storage randomly belong to the four (04) segments. Considering the signs of the values of the utility, the producers in segment 1 (S1) preferred very or less efficient expansive storage structures whose building materials were either imported or improved. This segment wanted to store maize as grains in long-lasting, small-capacity structures and structures with a long life span. The socio-demographic characteristic coefficients revealed that this segment is represented by male producers who were close to the market and never participated in improved storage structure trials. These male producers not only had a high income but also had access to credit, and they stored large quantities of maize for sale. Taking into account their remarks, all the attributes were determinant factors for the individuals in this segment. Indeed, the attributes that these farmers wanted were similar to those of metal silos and improved clay granaries with a capacity of $250 \mathrm{~kg}$. This segment was therefore called the "segment of large farmers with access to credit; users of small imported/improved, resistant, expansive structures; and maize grain keepers".

Segment 2 (S2) of the model was significantly characterized by male maize growers who were strongly inclined to store maize as grain in structures designed with local materials. These producers were willing to pay a high price for less or very effective small capacity structures that could serve them for a long time. The characteristics that these farmers looked for in a structure were similar to those of $250 \mathrm{~kg}$ traditional silos but were more effective in terms of loss reduction and durability. The socio-demographic coefficients revealed that these producers were poor farmers living very far from markets who had no access to credit. These producers never participated in trials related to 
improved storage structure. As a result, they were called the "segment of poor farmers with no access to credit; users of small but very efficient, resistant, expansive structures designed with local materials; and maize grain keepers".

The sign of the variable coefficient utility for segment 3 (S3) reveals that this group of farmers was also composed of men who were strongly dedicated to storing maize as grains, similar to the other segments (S1, S2, and S4). Unlike the producers in S2, those in S3 had access to credit; therefore, they were willing to pay a high price in order to benefit from imported and small-capacity, very efficient and resistant structures. In addition, they paid particular attention to all the attributes. The structure attributes sought by these farmers were similar to those of metallic silos, with a capacity equal to $250 \mathrm{~kg}$. These producers never participated in trials and were close to their markets. Thus, they were farmers with high incomes who stored small quantities of maize.

The sign of the variable coefficient utility for segment 4 (S4) revealed that this group of farmers included men and women interested in the storage of maize as grains in medium- or large-capacity structures (more than $250 \mathrm{~kg}$ ). These producers had similar preferences to the individuals in S1, who were willing to pay high prices for very efficient imported/improved structures. Unlike the producers in S1 and S4, they were attracted to small-capacity structures. The coefficient of the variable related to costs was not significant. This result indicates that these producers did not pay particular attention to the cost of the structure. However, the sign of the coefficient of the variable shows that they were willing to pay for structures whose life span is longer, regardless of the price. Therefore, the structure features that the farmers in S4 were seeking are similar to those of medium or large capacity metal and improved silos. With regard to the socio-economic characteristics of the farmers in S4, which is considered the reference segment, the coefficient parameters of these characteristics were interpreted by comparing them with the coefficients of the three (03) other segments, provided that all the coefficients had the same signs and were significant [27]. Indeed, the coefficient of the variable related to the connection with institutions had a negative sign and was significant for the three (03) first segments. Therefore, S4 was composed of men and women who had connections with institutions working on improved storage structures. This segment was therefore named the "segment of men and women using very efficient, expensive, and long-lasting, large-capacity imported/improved structures and maize grain keepers".

\subsection{Willingness to Pay for Structure Attributes by Segment}

The parameters estimated from the latent class logit model were used to calculate each segment's WTP for each attribute (Table 6) from the derivative monetary attribute related to the cost, which helps to understand the motivation of different stakeholders and quantify their level of preference.

Table 6. Willingness to Pay for Structural Attributes According to Segment.

\begin{tabular}{ccccc}
\hline & Segment 1 (FCFA) & Segment 2 (FCFA) & Segment 3 (FCFA) & Segment 4 (FCFA) \\
\hline Medium capacity $(250-500 \mathrm{~kg})\left(1^{*}\right)$ & $-82,187.74$ & -4190.26 & $-65,338.79$ & $171,576.91$ \\
Large capacity $(>500 \mathrm{~kg})\left(1^{*}\right)$ & -4504.46 & $-15,160.97$ & $-22,973.14$ & $206,581.46$ \\
Form of storage in the cob $\left(2^{*}\right)$ & $-23,126.61$ & -3469.58 & $-22,973.14$ & $-340,255.31$ \\
Form of storage as stalk $\left(2^{*}\right)$ & $-71,353.63$ & $-31,289.92$ & $-51,965.03$ & $-184,649.04$ \\
Less effective $\left(5-30 \%\right.$ loss) $\left(3^{*}\right)$ & $108,356.79$ & $16,463.85$ & $98,727.8$ & $361,867.26$ \\
Very effective $\left(<5 \%\right.$ loss) $\left(3^{*}\right)$ & 128,681 & $34,919.65$ & $100,499.57$ & $423,819.52$ \\
Type of materials: Improved $\left(4^{*}\right)$ & $49,174.15$ & $-50,802.42$ & $-810,308.4$ & $158,052.47$ \\
Type of materials: Imported $\left(4^{*}\right)$ & $10,778.40$ & -9592.91 & $213,298.85$ & $188,434.62$ \\
Long life span $(>4$ years) & $21,263.27$ & 9704.10 & 6753.76 & $215,452.78$ \\
\hline
\end{tabular}

$\left(1^{*}\right)$ Reference: low capacity (25-250 kg); ( $\left.2^{*}\right)$ Reference: storage as grain; ( $\left.3^{*}\right)$ Reference: less efficient ( $>30 \%$ loss);

$\left(4^{*}\right)$ Reference: Type of materials for building traditional storage structures.

The analysis in Table 6 reveals that the producer segments 1, 2 and 3 were ready to pay, respectively, an amount worth 82,187.73 FCFA (or 125.48 euros at a fixed exchange rate of 1 euro $=655$ FCFA); 4190.26 FCFA (or 6.40 euros); and 65,338.79 FCFA (99.75 euros) for a small-capacity rather than a 
medium-capacity structure $(250-500 \mathrm{~kg})$. The same trend was observed for the "high capacity (over $500 \mathrm{~kg}$ )" attribute for which the farmers in S1, S2, and S3 offered, respectively, 40,504.46 FCFA (61.83 euros), 15,160.971 FCFA (23.15 euros), and 22,973.14 FCFA (35.07 euros) to benefit from small-capacity structures (less than $250 \mathrm{~kg}$ ). However, the producers in S4 showed a stronger WTP for medium-capacity (171,576.91 FCFA or 261.94 euros) and large-capacity structures (206,581.46 FCFA or 315.39 euros).

Regarding the form of storage, the farmers in segments $1,2,3$ and 4 were ready to pay 23,126.60 FCFA (35.31 euros), 3,469.58 FCFA (5.30 euros), 22,973.14 FCFA (35.07 euros), and 340,255.31 FCFA (or 519,47 euros), respectively, to store maize as grain rather than cobs. The same trend was observed for the storage of maize as stalk in structures. The producers in S1, S2, S3, and S4 were also prepared to pay 128,681 FCFA (196.45 euros), 34,919.64 FCFA (53.31 euros), 100,499.57 FCFA (153.43 euros) and 423,819.52 FCFA (or 647.05 euros), respectively, to have very efficient structures with a loss rate of less than $5 \%$ compared to structures with a loss rate that exceeds $30 \%$. The same trend was observed for the attribute "less efficient", indicating that farmers in S1, S2, S3 and S4 wanted to pay less than the $84.20 \%, 47 \%, 98 \%, 85.38 \%$, respectively, WTP levels proposed for the attribute "very efficient" to benefit from less efficient structures (between 5-30\% loss). This result shows that highly efficient structures (with loss rates of less than $5 \%$ ) are preferred to less efficient structures.

In terms of the attribute related to improved building materials for the storage structures, the farmers in S1, S3 and S4 were willing to pay 49,174.14 FCFA (75.07 euros), 50,802.41 FCFA (77.56 euros), and 158,052.47 FCFA (or 241,30 euros), respectively. This attribute was less popular among the farmers in S3 (810.30 FCFA), indicating their reluctance to pay for structures designed with improved materials. In contrast, those in segment S2, given their low purchasing power and their lack of access to seasonal loans, showed a low WTP for attributes compared to individuals in the other segments (S1, S3 and S4). In addition, the individuals in S2 were ready to pay 50,802.41 FCFA, or 77.56 euros, to benefit from structures designed with local materials rather than those designed with improved materials. In the same way, they offered 9592.91 FCFA, or 14.65 Euros, to obtain structures made with local materials rather than imported materials.

Taking into account the attribute that specifies the life span, we noticed that producer segments 1 , 2, 3 and 4 were ready to pay 21,263.27 FCFA (32.46 euros), 9704.09 FCFA (14.85 euros), 6753.76 FCFA (10.31 euros) and 215,452.78 FCFA (328.93 euros), respectively, for structures with a service life of greater than four (04) years rather than those with a service life of less than four (04) years. The WTP values for attributes associated with structures whose building materials are imported, with high efficiency and a long service life for the storage of maize grain, were high compared to those of other attributes. The reason is that the majority of farmers gave much greater priority to these attributes. The segment 4 farmers showed a high WTP for all the attributes compared to individuals in the other segments (S1, S2 and S3). Therefore, the farmers in S4 were rich with access to credit.

\section{Discussion}

The four segments (S1, S2, S3 and S4) were, respectively, composed of $25.75 \%, 19.18 \%, 26.58 \%$ and $28.49 \%$ of the individuals included in the sample. The results show that the preferences were homogeneous regarding the storage of maize in the form of grain for all the producer segments. The producers thought that this form of storage facilitates not only the destocking for consumption or sale, but also allows the producers to make accurate estimates of the stock available in the structure, unlike other forms of storage (cob and stalk). Moreover, the farmers believed that small-capacity structures cannot contain a large quantity of maize in the form of cobs or stalk. The respondents' preferences were also homogenous for storage structures whose life span exceeds four (04) years. Indeed, they preferred to use storage structures that have a long service life for better economic performance across multiple harvests.

One difference appeared regarding the building or the purchase cost of the storage structure for segment 4 , which is composed of large maize farmers of both genders who are in contact with 
institutions working on improved storage structures. The high cost of a structure did not prevent these farmers from paying for it. This is explained by the fact that these farmers consider price to be an indicator of good quality. This result is not consistent with Maboudou's work [68], which showed that the higher the building cost of a granary, less farmers are willing to pay for it. This segment (S4) had the largest proportion of individuals (28.49\%) in the sample, and their preferences were directed to very efficient storage technologies (loss rate of less than $5 \%$ ) or less efficient storage technologies (loss rates between 5\% and 30\%) that use building materials that have been improved or imported. These results are consistent with the work of Adegbola and Gardebroek [62], which showed that maize farmers who have contact with extension agents, a cooperative or an agricultural association or those who produce a high quantity of maize are more likely to adopt new storage technologies. The farmers in S4 shared similar preferences to the individuals in segment 1 , who were male, large maize farmers with access to credit and were close to local markets. The latter segment (S1) represented $25.75 \%$ of the participants. Because of their level of prosperity and their easy access to credit, the farmers in S1 were willing to pay high prices for very efficient imported structures/improved structures with a loss rate of less than 5\%. These results are consistent with the work of Bhandari and et al. [69], which shows that improved crop storage favors the retention of quality with lower moisture content for year-long storage of maize. Difficulties in obtaining and collecting local materials to construct the structures (long distance or transport and scarcity of some materials) can limit the use of such structures $[54,56,58]$. In addition, farmers prefer using imported structures that are available, easy to handle and more efficient. The farmers believed that the efficiency or service life of a structure depends on the nature of the materials used to make it. That is why the farmers tended to prefer improved or modern quality, resistant or flame-proof equipment to ensure stock safety (against theft, pest attacks, and fires, etc.) and a longer service life for the structure. Indeed, the attributes desired by the individuals in segment 1 and segment 4 are similar to those of metal and improved mud silos. However, there is a heterogeneity of preference relating to storage capacity between these two (02) segments (S1 and S4). Indeed, those in S1 are attracted to small-capacity structures (less than $250 \mathrm{~kg}$ ), whereas those in S4 are attracted to medium-capacity structures (between $250 \mathrm{~kg}$ and $500 \mathrm{~kg}$ ) or large-capacity structures (more than $500 \mathrm{~kg}$ ). The farmers in segment 4 exhibited a higher WTP for all the attributes compared to the farmers in the other segments (S1, S2 and S3). The farmers in S4 can thus be considered rich farmers who have access to credit, hence, their preference for large-capacity structures. Production levels naturally determine the type of structure to use $[10,53]$. When the production is high, a farmer is eager to use a large-capacity storage technology.

Those in segment 1 were accustomed to storing large quantities of maize for sale and sought small-capacity structures. A structure should be filled to the top in order to take advantage of its performance. This result could thus be explained by the fact that yields are often unpredictable because of the effects of climate change. Therefore, these farmers are somewhat reluctant to build medium- and large-capacity structures rather than small-capacity structures, which may be more likely to achieve full performance. The farmers think that the acquisition cost of even a small-capacity silo is high and that the greater the capacity of the silo is, the higher its price.

The farmers in segment 3 represented $26.58 \%$ of the participants and were rich men who were accustomed to storing small quantities of maize, which explains their preference for small-capacity metal silos (less than $250 \mathrm{~kg}$ ). The attribute related to the improved nature of building materials was less popular among these farmers.

The respondents in segments 3 and 1 could easily access the market and sell agricultural products, which gave them substantial profits because they were close to periodic markets, unlike the farmers in segment 2. Those characteristics led these farmers to prefer modern, resistant, highly efficient structures that could reduce losses and that may improve product quality. Therefore, this type of structure may allow farmers to maintain their stocks for a long time until they are needed (i.e., during a shortage) and to thus achieve significant profit margins. These results are consistent with those of $[65,70,71]$. 
Moreover, these two (02) categories of farmers (segments 1 and 3) have access to credit that enables the purchase of expensive structures. However, the widespread adoption of very efficient structures (metal silos) by the farmers in this segment could be stimulated by incentives such as small loans to be paid back through two (02) production campaigns, for example. These results are consistent with those of $[62,72-74]$ These studies show that access to credit has been identified as the main reason justifying the success of the Swiss-funded grain storage project in Honduras. This project has distributed over 22,000 silos to more than 18,500 families with a high recovery rate. However, innovations that turned out to be cost-effective for farmers are disseminated by the private sector without the intervention of official organizations, as was the case with metal silos in Guatemala, Pakistan and Swaziland.

The farmers in segment 2 were relatively poor men who wanted to store maize grains in structures designed with local materials rather than improved/imported materials. In addition, they were ready to pay more for the attributes associated with structures designed with local materials compared to all the other attributes. The structure attributes that these farmers were looking for were similar to those of $250 \mathrm{~kg}$ traditional silos, but they sought structures that are resistant and very efficient in terms of loss reduction (less than 5\%). Since improved structures demand greater effort to obtain solid materials and to build $[59,75]$, these farmers were reluctant to choose these over silos or traditional structures that require much less effort. Additionally, their reluctance to select imported structures can be explained by the fact that they tend to value the resources/traditional practices in their community (or of their ethnicity) by using local materials that are freely available around their farms or areas and that have a proven efficiency over time. Compton et al. (1993) showed that structures designed with local materials can be used to simultaneously store multiple products, whereas silos designed with imported materials can store only one product. Note that structures with a loss rate between $5 \%$ and $30 \%$ were almost accepted by the farmers in S2. Considering their low purchasing power and lack of access to seasonal credit and markets, they preferred structures whose capacity is less than $250 \mathrm{~kg}$, and their WTP was less than that of the other segments (S1, S3 and S4). However, the S2 farmers valued very efficient small-capacity structures (loss rate below $5 \%$ ) that they can use for a long period (over 4 years). In addition, among all the attributes, the one related to the structure's efficiency represented the farmers' second most appreciated attribute in S2. Therefore, this attribute was also very important to them.

\section{Conclusions}

Maize is the major cereal staple food and an important source of income and employment for many farmers in Benin. It is stored in traditional storage structures at village level leading to high loss rates estimated to be between $17 \%$ and $40 \%$ of the total maize production after six months of storage. The storage granaries developed and promoted to reduce these losses are less adopted or disadopted a few years after use. This study postulated that the characteristics of storage structures are the basic factors in explaining the low adoption and the abandonment of these storage structures in Benin. Indeed, a storage structure is a bundle of characteristics and depending on their valuation by the producers, different preferences will be commanded. This study was therefore motivated by the desire to provide a better understanding of maize producers' preferences for storage structures and their characteristics so that a specific program could be designed to achieve a wide adoption and diffusion of new or improved granaries. To achieve this objective, we used a choice experiment (CE) approach. In addition, the latent class logit model (LCL) was applied to investigate heterogeneity among maize producers, based on their preferences for characteristics embodied in the profiles of storage structures. Moreover, the farmers' willingness to pay (WTP) for the storage structures or attributes is documented. Design attributes considered included structure capacity; storage shape; efficiency; building material type; life span; and initial investment and operation costs.

The results of the latent class logit model (LCL) identify and characterize four segments based on producers' preferences for storage structures and their specific characteristics. Three segments (S1, S3 and S4) assign the highest utility values to the high effectiveness of the storage structures against pest 
attacks (less than 5\%). Farmers in the segments S1 and S3 have access to credit and live close to the markets. In addition, they prefer metallic silos with a capacity of $250 \mathrm{~kg}$. Farmers in segment $\mathrm{S} 4$ seek medium- or large-capacity (more than $250 \mathrm{~kg}$ ) metal silos. On the other hand, segment S2 assigns the highest utility values to improved building materials. On the other hand, segment S2 assigns the highest utility values to preference to improved building materials. They consider that the efficiency or the hardness of a structure depends on the type of building materials. For this reason, they tend to prefer quality, resistant or flammable solids, improved or modern to guarantee the security of the stock (theft, pest attack, fires, etc.) and the hardness of the structure. They also prefer traditional silos of $250 \mathrm{~kg}$ with high effectiveness against pest attacks (less than 5\%). These producers are poor, live far from the market cities, and do not have any access to credit.

Since 2016, with the new government, Benin has taken the option to develop the agricultural sector through the seven (7) agricultural development poles (PDAs). Maize is an important crop in six of seven PDAs and is the country's staple food. Its production is higher in the north and center of the country, which serves the southern region of the country and exports the extra to Niger and Nigeria, the surrounding countries. Even though maize received huge support that increased the national production over five years, the losses remain high during storage due to the inappropriate storage structures and the high cost of efficient storage structures. The reduction of storage losses will ensure food availability for the population. Agricultural policy should therefore focus on ways of reducing losses by facilitating access to storage technologies considering the segments.

These results imply that the use of a domain recommendation approach to storage structures design is appropriate both from the perspective of the widespread adoption that can be achieved and the cost-effectiveness of agricultural extension services works. This will be combined with a client-oriented approach based on participatory on-farm trials of the storage innovations.

Author Contributions: E.G.-S., Y.P.A., G.B. and R.C.Z. designed the experiments. E.G.-S., Y.P.A. and R.C.Z. performed the experiments. E.G.-S. and R.C.Z. conducted, collected and analyzed the data. E.G.-S., Y.P.A., G.B. and R.C.Z. wrote the manuscript.

Funding: This research was funded by "Centre International de Recherches et de Formations en Sciences Sociales" (CIRFoSS).

Acknowledgments: We would like to sincerely thank CIRFoSS for their collaboration. We are grateful for the data collection contributions and advice on an earlier draft offered by ADEGBOLA Nadège (CIRFoSS) and CRINOT Fabrice (CIRFoSS). We are also grateful to the four reviewers for their relevant and constructive comments and suggestions.

Conflicts of Interest: The authors declare no conflict of interest.

\section{Appendix A}

Table A1. Ranking of the main attributes of storage technologies.

\begin{tabular}{cc}
\hline Attributes & Rank \\
\hline Capacity & $10.42(1)$ \\
Cost (FCFA) & $9.79(4)$ \\
Efficiency & $9.93(3)$ \\
Type of building material & $9.00(5)$ \\
Storage form & $10.08(2)$ \\
Life span (years) & $7.50(6)$ \\
Position in storage process & $5.21(7)$ \\
Need of lots of effort for building & $2.71(11)$ \\
Possibility to stock many cereals & $4.17(8)$ \\
Perfect airtightness/waterproofing & $4.00(9)$ \\
Need of important labor work for using & $2.29(12)$ \\
Necessity of using conservation product & $3.00(10)$ \\
Number of observations & 12 \\
W of Kendall & 0.73 \\
Chi2 $x^{2}$ (11) & $14.666^{* * *}$ \\
\hline Note ( . . Rank Significance thresholds: *** $1 \%$
\end{tabular}

Note ( . . ) : Rank; Significance thresholds: ${ }^{* *} 1 \%$. 
Table A2. Experiment design and frequency selection of profiles in each group.

\begin{tabular}{|c|c|c|c|c|c|c|c|c|}
\hline & Storage Technologies & Capacity & Storage Shape & Efficiency & $\begin{array}{c}\text { Building Materials } \\
\text { Types }\end{array}$ & Life Span (Years) & $\begin{array}{c}\text { Cost } \\
\text { (FCFA) }\end{array}$ & $\begin{array}{c}\text { Fre-Quency } \\
(\%)\end{array}$ \\
\hline \multirow{5}{*}{ Group 1} & Profile 1 & Medium (250-500 kg) & Cobs & Less effective (5-30\% loss) & Imported & short $(<4$ years $)$ & 15,000 & 10.41 \\
\hline & Profile 2 & Small $(25-250 \mathrm{~kg})$ & Stalk & Very effective (<5\% loss) & Traditional & long ( $>4$ years) & 25,000 & 10.41 \\
\hline & Profile 3 (Traditional Clay Granary) & Large (>500 kg) & Grain & Ineffective (>30\% loss) & Traditional & short ( $<4$ years) & 40,000 & 1.92 \\
\hline & Profile 4 (Improved Clay Granary) & Medium (250-500 kg) & Grain & Less effective (5-30\% loss) & Improved & long ( $>4$ years) & 50,000 & 42.47 \\
\hline & Status q0 & $\begin{array}{l}\text { Large }(>500 \mathrm{~kg}) \text { or } \\
\text { Medium }(250-500 \mathrm{~kg}) \\
\text { or Small }(25-250 \mathrm{~kg})\end{array}$ & $\begin{array}{l}\text { Grain or Cobs } \\
\quad \text { or Stalk }\end{array}$ & $\begin{array}{l}\text { Ineffective }(>30 \% \text { loss) or } \\
\text { Very effective }(<5 \% \text { loss) or } \\
\text { Less effective ( } 5-30 \% \text { loss) }\end{array}$ & $\begin{array}{l}\text { Imported or } \\
\text { Improve or } \\
\text { Traditional }\end{array}$ & $\begin{array}{l}\text { long ( }>4 \text { years) or } \\
\text { short (<4 years) }\end{array}$ & & 34.79 \\
\hline \multirow{5}{*}{ Group 2} & Profile 5 (Metal Silo of 1 ton) & Large $(>500 \mathrm{~kg})$ & Grain & Very effective $(<5 \%$ loss $)$ & Imported & long ( $>4$ years) & 110,000 & 81.10 \\
\hline & Profile 6 & Medium $(250-500 \mathrm{~kg})$ & Stalk & Less effective (5-30\% loss) & Traditional & short ( $<4$ years) & 20,000 & 1.64 \\
\hline & Profile 7 & Medium (250-500 kg) & Cobs & Ineffective (>30\% loss) & Improved & long ( $>4$ years) & 20,000 & 0.27 \\
\hline & Profile 8 & Small $(25-250 \mathrm{~kg})$ & Stalk & Very effective $(<5 \%$ loss $)$ & Imported & short $(<4$ years $)$ & 10,000 & 7.04 \\
\hline & Status q0 & $\begin{array}{l}\text { Large }(>500 \mathrm{~kg}) \text { or } \\
\text { Medium }(250-500 \mathrm{~kg}) \\
\text { or Small }(25-250 \mathrm{~kg})\end{array}$ & $\begin{array}{l}\text { Grain or Cobs } \\
\text { or Stalk }\end{array}$ & $\begin{array}{l}\text { Ineffective ( }>30 \% \text { loss) or } \\
\text { Very effective }(<5 \% \text { loss }) \text { or } \\
\text { Less effective }(5-30 \% \text { loss })\end{array}$ & $\begin{array}{l}\text { Imported or } \\
\text { Improve or } \\
\text { Traditional }\end{array}$ & $\begin{array}{l}\text { long (>4 years) or } \\
\text { short (<4 years) }\end{array}$ & & 9.95 \\
\hline \multirow{5}{*}{ Group 3} & Profile 9 & Large $(>500 \mathrm{~kg})$ & Cobs & Very effective $(<5 \%$ loss $)$ & Imported & long (>4 years) & 45,000 & 46.58 \\
\hline & Profile 10 (Improved Vegetal materials Granary) & Large $(>500 \mathrm{~kg})$ & Stalk & Less effective (5-30\% loss) & Traditional & long ( $>4$ years) & 37,000 & 9.86 \\
\hline & Profile 11 & Medium $(250-500 \mathrm{~kg})$ & Grain & Ineffective (>30\% loss) & Improved & long ( $>4$ years) & 15,000 & 1.37 \\
\hline & Profile 12 (Improved wood granary) & Medium $(250-500 \mathrm{~kg})$ & Cobs & Less effective (5-30\% loss) & Improved & long ( $>4$ years) & 31,000 & 7.12 \\
\hline & Status q0 & $\begin{array}{l}\text { Large }(>500 \mathrm{~kg}) \text { or } \\
\text { Medium }(250-500 \mathrm{~kg}) \\
\text { or Small }(25-250 \mathrm{~kg})\end{array}$ & $\begin{array}{l}\text { Grain or Cobs } \\
\quad \text { or Stalk }\end{array}$ & $\begin{array}{l}\text { Ineffective }(>30 \% \text { loss }) \text { or } \\
\text { Very effective }(<5 \% \text { loss) or } \\
\text { Less effective }(5-30 \% \text { loss })\end{array}$ & $\begin{array}{l}\text { Imported or } \\
\text { Improve or } \\
\text { Traditional }\end{array}$ & $\begin{array}{l}\text { long ( }>4 \text { years) or } \\
\text { short (<4 years) }\end{array}$ & & 35.07 \\
\hline \multirow{5}{*}{ Group 4} & Profile 13 (PICS bag or Zerofly bag $<0.25$ tons) & Small $(25-250 \mathrm{~kg})$ & Grain & Very effective $(<5 \%$ loss $)$ & Imported & short ( $<4$ years) & 2500 & 39.18 \\
\hline & Profile 14 (Metal silo: 0.35 and 0.5 tons) & Medium $(250-500 \mathrm{~kg})$ & Grain & Very effective $(<5 \%$ loss $)$ & Imported & long ( $>4$ years) & 71,500 & 51.23 \\
\hline & Profile 15 & Large $(>500 \mathrm{~kg})$ & Stalk & Ineffective ( $>30 \%$ loss) & Imported & long ( $>4$ years) & 35,000 & 0.27 \\
\hline & Profile 16 & Medium (250-500 kg) & Cobs & Very effective $(<5 \%$ loss $)$ & Imported & short ( $<4$ years $)$ & 20,000 & 1.92 \\
\hline & Status q0 & $\begin{array}{l}\text { Large }(>500 \mathrm{~kg}) \text { or } \\
\text { Medium }(250-500 \mathrm{~kg}) \\
\text { or Small }(25-250 \mathrm{~kg})\end{array}$ & $\begin{array}{l}\text { Grain or Cobs } \\
\text { or Stalk }\end{array}$ & $\begin{array}{l}\text { Ineffective }(>30 \% \text { loss }) \text { or } \\
\text { Very effective }(<5 \% \text { loss) or } \\
\text { Less effective }(5-30 \% \text { loss })\end{array}$ & $\begin{array}{l}\text { Imported or } \\
\text { Improve or } \\
\text { Traditional }\end{array}$ & $\begin{array}{l}\text { long ( }>4 \text { years) or } \\
\text { short }(<4 \text { years) }\end{array}$ & & 7.40 \\
\hline \multirow{5}{*}{ Group 5} & Profile 17 (Traditional bamboo/palm Granary) & Medium $(250-500 \mathrm{~kg})$ & Stalk & Ineffective ( $>30 \%$ loss) & Traditional & short ( $<4$ years) & 20,000 & 1.92 \\
\hline & Profile 18 & Large (>500 kg) & Cobs & Less effective (5-30\% loss) & Imported & long ( $>4$ years) & 45,000 & 7.12 \\
\hline & Profile 19 (Plastic cans $<0.25$ tons) & Small (25-250 kg) & Grain & Very effective (<5\% loss) & Imported & long ( $>4$ years) & 600 & 52.88 \\
\hline & Profile 20 & Medium $(250-500 \mathrm{~kg})$ & Grain & Very effective $(<5 \%$ loss $)$ & Improved & short $(<4$ years $)$ & 25,000 & 16.71 \\
\hline & Status q0 & $\begin{array}{l}\text { Large }(>500 \mathrm{~kg}) \text { or } \\
\text { Medium }(250-500 \mathrm{~kg}) \\
\text { or Small }(25-250 \mathrm{~kg})\end{array}$ & $\begin{array}{l}\text { Grain or Cobs } \\
\text { or Stalk }\end{array}$ & $\begin{array}{l}\text { Ineffective }(>30 \% \text { loss }) \text { or } \\
\text { Very effective }(<5 \% \text { loss }) \text { or } \\
\text { Less effective }(5-30 \% \text { loss })\end{array}$ & $\begin{array}{l}\text { Imported or } \\
\text { Improve or } \\
\text { Traditional }\end{array}$ & $\begin{array}{l}\text { long ( }>4 \text { years) or } \\
\text { short (<4 years) }\end{array}$ & & 21.37 \\
\hline
\end{tabular}




\section{References and Notes}

1. Gustavason, J.; Cederberg, C.; Van Otterdijk, R.; Meybeck, A. Pertes et Gaspillages Alimentaires dans le Monde; Étude Menée pour le Congrès International; FAO: Rome, Italy, 2011; 41p.

2. FAO. Tropical Fruits Conpendium; FAO: Rome, Italy, 2011.

3. World Bank. Missing Food: The Case of Postharvest Grain Losses in Sub-Saharan Africa; Report No. 60371-AFR; World Bank: Washington, DC, USA, 2011.

4. Stathersa, T.E.; Chigarirob, J.; Mudivac, B.M.; Golob, P. Small-scale farmers perceptions of diatomaceous earth products as potential stored grain proctectant in Zimbabwe. Crop Prot. 2002, 21, 1049-1060. [CrossRef]

5. Tefera, T.; Kanampiu, F.; De Groote, H.; Hellin, J.; Mugo, S.; Kimenju, S.; Beyene, Y.; Boddupalli, P.M.; Shiferaw, B.; Banziger, M. The metal silo: An effective grain storage technology for reducing post-harvest insect and pathogen losses in maize while improving smallholder farmers' food security in developing countries. Crop Prot. 2011, 30, 240-245. [CrossRef]

6. Rembold, F.; Hodges, R.; Bernard, M.; Knipschild, H.; Léo, O. The African Postharvest Losses Information System (APHLIS) An Innovative Framework to Analyse and Compute Quantitative Postharvest Losses for Cereals under Different Farming and Environmental Conditions in East and Southern Africa; Technical Report; Publications Office of the European Union: Luxembourg, 2011.

7. Centre de Partenariat et Expertise Pour le Development Durable (CEPED). Etude Pilote Pour L'actualisation des Normes de Consommation des Principaux Produits Vivriers au Bénin; 2010.

8. Kossou, D.K.; Aho, N. Stockage et Conservation des Grains Alimentaires Tropicaux: Principes et Pratiques; Les Editions du Flamboyant: Cotonou, Bénin, 1993.

9. Affognon, H.; Kossou, D.; Bell, A. Développement Participatif de Technologies Post-Récolte au Bénin; Rapport; Deutsche Gesellschaft für Technische Zusammenarbeit: Eschborn, Germany, 2000.

10. Adegbola, Y.P. Economic Analyses of Maize Storage Innovations in Southern Benin. Ph.D. Thesis, Wageningen University, Wageningen, The Netherlands, 2010; p. 191. Available online: http://edepot. wur.nl/137893 (accessed on 12 July 2014).

11. Adegbola, Y.P.; Arouna, A.; Ahoyo, N. Analyse des Facteurs Affectant L'adoption des Greniers Améliorés pour le Stockage du Maïs au Sud-Bénin; Numéro Special 2, Aspects economiques du stockage et de la conservation du Maïs au sud-Benin; Bulletin de la Recherche Agronomique du Benin: Benin, September 2011; pp. 43-50.

12. Arouna, A.; Adegbola, P.Y.; Biaou, G. Analyse des coûts de Stockage et de Conservation du Maïs au Sud-Bénin; Numéro Special 2, Aspects economiques du stockage et de la conservation du Maïs au sud-Benin; Bulletin de la Recherche Agronomique du Benin: Benin, September 2011; pp. 13-23.

13. Adebayo, M.A.; Menkir, A.; Blay, E.; Gracen, V.; Danquah, E.; Hearne, S. Genetic analysis of drought tolerance in adapted exotic crosses of maize inbred lines under managed stress conditions. Euphytica 2013, 196, 261-270. [CrossRef]

14. Batz, F.-J.; Janseen, W.; Peters, K.J. Predicting technology adoption to improve research priority-setting. Agric. Econ. 2003, 28, 151-164.

15. Negatu, W.; Parikhb, A. The impact of perception and other factors on the adoption of agricultural technology in the Moret and Jiru Woreda (district) of Ethiopia. Agric. Econ. 1999, 21, 205-216. [CrossRef]

16. Llewellyn, R.S.; Lindner, R.K.; Pannell, D.J.; Powles, S.B. Grain grower perceptions and use of integrated weed management. Aust. J. Exp. Agric. 2004, 44, 993-1001. [CrossRef]

17. Wossink, G.A.A.; de Buck, A.J.; van Niejenhuis, J.H.; Haverkamp, H.C.M. Farmers perceptions of weed control techniques in sugarbeet. Agric. Syst. 1997, 55, 409-423. [CrossRef]

18. Sall, S.; Norman, D.; Featherstone, A.M. Quantitative assessment of improved rice variety adoption: The farmer's perspective. Agric. Syst. 2000, 66, 129-144. [CrossRef]

19. Reed, G.V.; Binks, M.R.; Ennew, C.T. Matching the characteristics of a service to the preferences of customers. Manag. Decis. Econ. 1991, 12, 231-240. [CrossRef]

20. Baidu-Forson, J.; Ntare, B.R.; Waliyar, F. Utilizing coinjoint analysis to design modern crop varieties: Empirical example for groundnut in Niger. Agric. Econ. 1997, 16, 219-226. [CrossRef]

21. Hamath, A.S.; Famivow, D.M.; Johnson, V.G.; Crow, G. Estimating the values of cattle characteristics using an ordered probit model. Am. J. Agric. Econ. 1997, 79, 463-476. 
22. Chen, K.; Ali, M.; Veeman, M.; Unterschultz, J.; Le, T. Relative importance rankings for pork attributes by Asian-origin consumers in Califormia: Applying an ordered probit model to a choice-based sample. J. Agric. Appl. Econ. 2002, 34, 67-79. [CrossRef]

23. Kouadio, T.; Kamuanga, M.; Faminow, M.D.; Swallow, B. Analysis using conjoint analysis to estimate farmer's preferences for cattle traits in West Africa. Ecol. Econ. 2003, 45, 393-407.

24. Ndjeunga, J.; Nelson, C.H. Towards understanding household preference for consumption characteristics of millet varieties: A case study from western Niger. Agric. Econ. 2005, 21, 151-165. [CrossRef]

25. Cembalo, L.; Ciciaet, G.; Giudice, T.D. The influence of country of origin on German consumer preferences for peaches: A latent class choice model. In Proceedings of the 113th EAAE Seminar "A Resilient European Food Industry and Food Chain in a Challenging World", Chania, Crete, Greece, 3-6 September 2009.

26. Faustin, V.; Adegbidi, A.; Garnett, S.T.; Koudandé, D.O.; Agbo, V.; Zander, K.K. Peace, health or fortune? Preference for chicken traits in rural Benin. Ecol. Econ. 2010, 69, 1848-1857. [CrossRef]

27. Birol, E.D.; Asare-Marfoet, D.R. A Latent Class Approach to Investigating Farmer Demand for Bio fortified Staple Food Crops in Developing Countries: The Case of High-Iron Pearl Millet in Maharashtra, India; Harvest Plus Working Paper No. 7; International Food Policy Research Institute (IFPRI): Washington, DC, USA, 2011.

28. Dangbedji, J.C. Evaluation Agroenvironnementale et Économique Intégrée de Scénarii de Pratiques de Gestion Bénéfiques. Master's Thesis, Université Laval, Québec, QC, Canada, 2014; p. 92.

29. Houessionon, P.; Fonta, W.M.; Bossa, A.Y.; Sanfo, S.; Thiombiano, N.; Zahonogo, P.; Yameogo, T.B.; Balana, B. Economic Valuation of Ecosystem Services from Small-Scale Agricultural Management Interventions in Burkina Faso: A Discrete Choice Experiment Approach. Sustainability 2017, 9, 1672. [CrossRef]

30. Damien, P. Mise en place d'enquêtes par préférences déclarées dans le cadre de projets d'études relatifs au secteur des transports de personnes; Thesis Réalisée au sein du Laboratoire D'économie des Transports, Unité Mixte de Recherche Rattaché au Centre National de la Recherche Scientifique (UMR No. 5593). Ph.D. Thesis, Université Lumière-Lyon II, Lyon, France, 2011.

31. Kouwenhoven, M. Incidence de L'accessibilité sur le Choix des Aéroports, Centre Conjoint de Recherche sur les Transports. 2008; p. 14.

32. Louviere, J.J.; Hensher, D.A.; Swait, J.D.; Adamowicz, W.L. Stated Choice Methods: Analysis and Applications; Cambridge University Press: Cambridge, UK, 2000.

33. (United Nations Development Programme) PNUD. Rapport National sur le Développement Humain (RNDH); Agriculture, Sécurité Alimentaire et Développement Humain au Benin; The United Nations in Benin: Benin, 2015; 144p.

34. Institut National des Recherches Agricoles du Bénin (INRAB)/PAPA. Caractérisation et Évaluation des Milieux Homogènes des Zones Agroécologiques du Bénin; Institut National des Recherches Agricoles du Bénin (INRAB): Cotonou, Benin, 2016; 307p.

35. Dillman, D.A. Mail and Internet Surveys_The Tailored Design Method, 2nd ed.; Wiley: New York, NY, USA, 2007.

36. Bonnichsen, O.; Ladenburg, J. Reducing status quo bias in choice experiments. Nord. J. Health Econ. 2015, 3, 47-67. [CrossRef]

37. Lancaster, J.K. A new approach to consumer theory. J. Polit. Econ. 1966, 74, 132-157. [CrossRef]

38. Tapsoba, D.-H. Une Estimation du Choix des Consommateurs Canadiens en Matière de Véhicules Personnels, de Nouvelles Technologies et de Carburants de Remplacement par Logit Mixte. Master's Thesis, Université Laval, Québec, QC, Canada, 2007.

39. Hall, J.; Viney, R.; Haa, M.; Louviere, J.J. Using stated preference discrete choice modelling to evaluate health care programs. J. Bus. Res. 2004, 57, 1026-1032. [CrossRef]

40. Desmet, P. Analyse Conjointe: Reconstituer Les Choix Déclaratifs Effectués par des Consommateurs au Sein de Plans Expérimentaux, Présentation Mémoire de Master en Marketing; Université Paris Dauphine: Paris, France, $2011 ; 27$.

41. Mennecke, B.E.; Townsend, A.M.; Hayes, D.J.; Lonergana, S.M. A Study of the Factors that Influence Consumer Attitudes toward Beef Products Using the Conjoint Market Analysis Tool. J. Anim. Sci. 2007, 85, 2639-2659. Available online: http:/ /jas.fass.org (accessed on 23 May 2014). [CrossRef] [PubMed]

42. Guyon, H. L'analyse Conjointe Discrète: Une Illustration Pour le Marché du Pneu; Pesor, Université Paris Sud 11: Orsay, France, 2010; 17p. 
43. Gill, J.M.; Sánchez, M. Consumer preferences for wine attributes: A conjoint approach. Br. Food J. 1997, 99, 3-11. [CrossRef]

44. Louvrière, J.J.; Woodworth, G.G. Design and analysis of simulated consumer choice or allocation experiments: An approach based on aggregate data. J. Mark. Res. 1983, 20, 350-367. [CrossRef]

45. Train, K.E. Recreation demand Models with taste Differences over peoples. Land Econ. 1998, 74, $230-239$. [CrossRef]

46. Ben-Akiva, M.; Bierlaire, M. Discrete choice methods and their applications to short term travel decisions. In Handbook of Transportation Science; Massachusetts Institute of Technology (MIT): Cambridge, MA, USA, 1999.

47. McFadden, D. Econometric analysis of qualitative responses models. In Handbook of Econometrics; Heckman, J.J., Griliches, Z., Leamer, E.E., Intriligator, M.D., Eds.; Elvesier: Amsterdam, The Netherlands, 1984; Chapter 24; Volume 2, pp. 1395-1457. Available online: https:/ /www.elvesier.com (accessed on 6 April 2005).

48. Henscher, D.A.; Greene, W.H. The Mixed Logit model: The state of practice. Transportation 2003, 30, $133-176$. [CrossRef]

49. Vidogbena, F.; Martin, T.; Saidi, M.; Assogba Komlan, F.; Simon, S.; Kasina, M.; Parrot, L.; Adegbidi, A.; Wasilwa, L.A.; Subramanian, S. Des filets pour protéger les cultures maraichères en Afrique Sub-Saharienne. Ecol. Econ. 2010, 69, 1848-1857.

50. Espinosa-Goded, M.; Barreiro-Hurle, J.; Ruto, E. What Do Farmers Want From Agri-Environmental Scheme Design? A Choice Experiment Approach. J. Agric. Econ. 2009, 61, 259-273. [CrossRef]

51. Hole, A.R. Mixed logit modeling in Stata-An overview. In Proceedings of the 19th London Stata Users Group Meeting, Cass Business School, London, UK, 12-13 September 2013.

52. Johnson, F.R.; Lancsar, E.; Marshall, D.; Vikram, K.; Regier Muhlbacher, A.; Regier, D.A.; Bresnahan, W.B.; Barbara, K.; Bridges, J.F.P. Constructing experimental designs for discrete-choice experiments: Report of the ISPOR Conjoint Analysis Experimental Design Good Research Practices Task Force. Value Health. 2013, 16, 3-13. [CrossRef] [PubMed]

53. Gueye, M.T.; Seck, D.; Wathel, J.; Lognay, G. Typologie des systèmes de stockage et de conservation du Maïs dans l'est et le sud du Sénégal. Biotechnol. Agron. Soc. Environ. 2012, 16, 49-58.

54. Fandohan, P. Introduction du Grenier Fermé en Tterre au Sud-Bénin pour le Stockage du Maïs; Rapport Technique de la Recherche; Institut National des Recherches Agricoles du Bénin (INRAB): Cotonou, Benin, 2000.

55. Schneider, K. Étude de Faisabilité pour la Promotion de Technologies Post-Récolte Améliorées dans Deux Régions du Bénin; Rapport de Mission; Helvetas Swiss Intercooperation: Cotonou, Bénin, 2015; 26p.

56. Food and Agriculture Organization (FAO). Difficultés-Acceptabilité-Eléments de Coûts des Techniques Améliorées de Stockage; Projet BEN/87/017; Systèmes de Stockage Décentralisé; FAO: Rome, Italy, 1992.

57. Fiagan, Y.S. Les Systèmes de Stockage de Mä̈s en Milieu Paysan Béninois: Bilan et Perspectives; CIRAD—FAS/UNB; FAO: Rome, Italy, 1994; 12p.

58. Food and Agriculture Organization (FAO). Rapport Technique sur les Expérimentations du Stockage Villageois Amélioré du Maïs (Zones du Zou-Nord et du Nord du Bénin); FAO: Rome, Italy, 1994; p. 10.

59. Adegbola, P.; Sissinto, E.; Hessavi, P.; Ohouko, O.K. Efficacité et Acceptabilité de Structures de Stockage du Maïs dans les Communes de Savalou et de Boukombé au Bénin; Rapport Technique de Recherches; Helvetas Swiss Intercooperation: Cotonou Bénin, 2017; 62p.

60. Compton, J.A.F.; Tyler, P.S.; Hindmarsh, P.S.; Golob, P.; Boxall, R.A.; Haines, C.P. Reducing losses in small farm grain storage in the tropics. Trop. Sci. 1993, 33, 283-318.

61. Pacifico, D.; Yoo, H. A Stata Module for Estimating Latent Class Conditional Logit Models via the Expectation-Maximization Algorithm; Paper No. 2012 ECON 49; UNSW Australian School of Business Research: Sydney, Australia, 2012.

62. Adegbola, P.; Gardebroek, C. The effect of information sources on technology adoption and modification decisions. Agric. Econ. 2007, 37, 55-65. [CrossRef]

63. Thangata, P.H.; Alavalapati, J.R.R. Agroforestry adoption in southern Malawi: The case of mixed intercropping of Gliricidia sepium and maize. Agric. Syst. 2003, 78, 57-71. [CrossRef]

64. PSRSA. Plan Stratégique de Relance du Secteur Agricole. 2011, p. 116. Available online: http:/ / extwprlegs1. fao.org/docs/pdf/ben149176.pdf (accessed on 2 October 2017). 
65. Maboudou, A.G. Adoption et Diffusion de Technologies Améliorées de Stockage du Maïs en Milieu Paysan dans le Centre et le Nord du Bénin; Mémoire Pour L'obtention du Diplôme D’etudes Approfondies; Université de Lomé, Faculté des Lettres et Sciences Humaines/Institut International d'Agriculture Tropicale: Lome, Togo, 2003; p. 108.

66. Addo, S.; Birkinshaw, L.A.; Hodges, R.J. Ten years after the arrival in Ghana of Larger Grain Borer: Farmers' responses and adoption of IPM strategies. Int. J. Pest Manag. 2002, 48, 315-325. [CrossRef]

67. Coulibaly, O.; Nkamleu, G.B.; Tamo, M.; Ngeve, J. Adoption of Storage Pest-Control Technologies Cowpea Traders in Western Cameroon: A Probit Model Application; International Institute of Tropical Agriculture: Ibadan, Nigeria, 2000.

68. Maboudou, A.G.; Adegbola, P.Y.; Coulibaly, O.; Hell, K.; Amouzou, E. Factors affecting the use of improved clay store for maize storage in the central and northern Benin. In New Directions for a Diverse Planet, Proceedings of the 4th International Crop Science Congress, Brisbane, Australia, 26 September-1 October 2004; Fischer, T., Ed.; Crop Science Society of America: Madison, WI, USA, 2004.

69. Bhandari, G.; Bahadur, G.; Kaduwal, S.; Shrestha, J.; Acharya, R. Effects of storage structures and moisture contents on seed quality attributes of quality protein maize. J. Maize Res. Dev. 2017, 3, 77-85. [CrossRef]

70. Adesina, A.A. Factors affecting the adoption of fertilizers by rice farmers in Côte d'Ivoire. Nutr. Cycl. Agroecosyst. 1996, 46, 29-39. [CrossRef]

71. Sanginga, P.C.; Adesina, A.A.; Manyong, V.M.; Otite, O.; Dashiell, K.E. Social Impact of Soybean in Nigeria's Southern Guinea Savanna; International Institute of Tropical Agriculture: Ibadan, Nigeria, 1999.

72. Hagos, F.; Aster, G.; Lulseged, T.; Schmitter, P.; Tegegne, D. Innovation Adoption for Scaling: Africa RISING Science, Innovations and Technologies with Scaling Potential from the Ethiopian Highlands. 2017. Available online: https: / cgspace.cgiar.org/bitstream/handle/10568/80067 / AR_eth_iwmi_Jan2017.pdfsequence=1 (accessed on 28 June 2018).

73. Tarfasa, S.; Balana, B.; Teferac, T.; Woldeamanuel, T. Modeling Smallholder Farmers' Preferences for Soil Management Measures: A Case Study from South Ethiopia. Ecol. Econ. 2018, 145, 410-419. [CrossRef]

74. Zulfiqar, F.; Thapa, G. Determinants and intensity of adoption of "better cotton" as an innovative cleaner production alternative. J. Clean. Prod. 2018, 172, 3468-3478. Available online: https://doi.org/10.1016/j. jclepro.2017.09.024 (accessed on 28 June 2018). [CrossRef]

75. Ram, H.; Balwinder, N.K.; Kaur, A. Resource-Conserving Technologies for Enhancing Resource Use Efficiency and Crop Productivity. In 2018 Eco-Friendly Agro-Biological Techniques for Enhancing Crop Productivity; Springer: Singapore, 2018; pp. 129-145. 